\title{
Preference mapping of commercial Labneh (strained yogurt) products in the Lebanese market
}

\author{
D. Kaaki, O. Kebbe Baghdadi, N. E. Najm, and A. Olabi ${ }^{1}$ \\ Nutrition and Food Sciences Department, Faculty of Agricultural and Food Sciences, American University of Beirut, Riad El Solh 11072020 , \\ Beirut, Lebanon
}

\begin{abstract}
Labneh or strained yogurt is a fermented milk product popular in Lebanon, the Middle East, and in the Balkan regions. With increased consumer awareness about the health benefits of consuming diets low in fat, reducedfat Labneh products have emerged on the Lebanese market. The objectives of this study were to assess the physicochemical and sensory properties of commercial bovine Labneh products differing in fat content. Seven commercial bovine Labneh brands were chosen. Three brands were available in full-fat, reduced-fat, and zerofat versions, 3 in full-fat and zero-fat versions, and 1 in full-fat and reduced-fat versions, resulting in a total of 17 tested samples. The moisture, fat, protein, ash, $\mathrm{pH}$, and nitrogen-free extract contents were determined and instrumental texture characteristics measured using a texture analyzer. Nine trained panelists used quantitative descriptive analysis to profile the sensory attributes of the samples and an acceptability test was carried out with 73 panelists. Brand type had a significant effect on all chemical parameters, as did fat level, except for nitrogen-free extract. Instrumental texture analysis showed a significant effect of brand and fat levels, as well as their interaction, on all attributes, except for adhesiveness and fat level. Sensory analysis suggested that significant differences existed between brands for most attributes. Full-fat samples were significantly more yellow, less sweet, and possessed a stronger acidic aftertaste than did their reduced-fat and zero-fat counterparts. Acceptability clearly decreased as fat level decreased from full fat to zero fat, with full-fat Labneh samples rating highest on the acceptability of appearance, flavor, texture, and overall acceptability.
\end{abstract}

Key words: preference mapping, Labneh, fat, bovine

Received March 31, 2011.

Accepted October 2, 2011.

${ }^{1}$ Corresponding author: ammar.olabi@aub.edu.lb

\section{INTRODUCTION}

Concentrated yogurt, known as Labneh in the Middle East and as strained yogurt in Europe, is a fermented milk product popular in the Middle East and Balkan regions, where it is widely consumed as a sandwich spread (Özer, 2006). It is a semi-solid product derived from yogurt by draining away part of its water and water-soluble components. The total solids and fat contents of Labneh are typically 23 to $25 \mathrm{~g} / 100 \mathrm{~g}$ and 10 $\mathrm{g} / 100 \mathrm{~g}$, respectively, and the product is characterized by a cream or white color, a soft and smooth body, good spreadability, and a flavor that is clean and slightly acidic (Nsabimana et al., 2005). Different types of milk can be used in the production of Labneh; namely, cow, sheep, and goat milks, although cow and, to a lesser extent, goat are more common (Tamime and Robinson, 2007). Labneh is traditionally produced by straining natural or plain full-fat yogurt in cloth bags until the desired level of total solids is achieved. However, the cloth bag method has many disadvantages compared with large- or factory-scale operations. It is slow, labor intensive, and unhygienic, and produces low yields because of residues left in the bag (Tamime and Robinson, 2007). Modern Labneh manufacturing methods include the use of centrifugation, recombination technology, and ultrafiltration (Nsabimana et al., 2005). Recently, the increase in popularity of Labneh in Europe has led to more interest in the structure of this product, especially in relation to the type of milk and different concentration techniques used in its production (Özer et al., 1999; Özer and Robinson, 1999; Malek et al., 2001; Abu-Jdayil et al., 2002; Mohameed et al., 2004). Moreover, higher awareness of the perceived health risks associated with the consumption of diets high in fat has fueled the growing consumer demand for low-fat products and led to an increase in the production of reduced-fat varieties of Labneh (Abou Jaoude et al., 2010). Because fat plays an essential role in modifying the physical properties of food, including mouthfeel, appearance (gloss, color, opacity), and structure (texture, consistency, melting profile), and is an important flavor precursor and flavor carrier (Brauss et al., 1999), 
producing low-fat foods with a flavor similar to that of their high-fat counterparts has proved somewhat difficult (Hatchwell,1994). Several Labneh products differing in texture, fat content, and sensory characteristics can be found on the Lebanese market.

This work aimed at assessing the characteristics of Labneh, an essential step to encourage industry professionals to apply appropriate technologies to produce Labneh products that possess physical and sensory properties comparable to those of the full-fat counterparts. The objectives of this work were to assess the physicochemical and sensory properties of commercial bovine Labneh products differing in fat content and to relate the acceptance of the different products to their sensory and physicochemical properties through texture analysis and internal and external preference mapping.

\section{MATERIALS AND METHODS}

\section{Samples}

Seven Labneh brands with different fat levels were selected and purchased from various large supermarkets located in the Beirut and Bekaa areas (Chtaura) of Lebanon. Only 3 brands were available in all 3 fat levels (full-fat, reduced-fat, and zero-fat). Three other brands were available in both full- and zero-fat levels and one brand in full- and reduced-fat levels; the total number of samples was 17. Labneh samples were all of bovine origin and were purchased in $0.5-\mathrm{kg}$ plastic containers 1 or $2 \mathrm{~d}$ before chemical, textural, and sensory tests were conducted. All samples were collected within their first week of production and in most cases were 2 to $3 \mathrm{~d}$ old. They were stored in the walk-in cooler of the pilot plant at the American University of Beirut at a temperature of $5^{\circ} \mathrm{C}$. Labneh samples used for protein were stored at $-20^{\circ} \mathrm{C}$.

\section{Chemical Analyses}

Representative Labneh samples were selected from each $0.5-\mathrm{kg}$ plastic container after mixing the contents thoroughly with a spoon. The methods of AOAC (2000) were used to determine moisture and ash contents (method 948.12), fat content (method 933.05), and protein content (method 920.125). The percentage of protein was calculated using a conversion factor of 6.38. All determinations were carried out in triplicate.

\section{Instrumental Texture Analysis}

The evaluation of textural properties was conducted by using a texture analyzer (QTS25, Brookfield En- gineering Labs, Middleboro, MA) using the backward extrusion test. Each Labneh sample was mixed gently with a spoon in order not to lose the textural characteristics before testing. Forty grams of sample was transferred to the cylindrical glass probe $(5 \mathrm{~cm}$ diameter, 4.5 $\mathrm{cm}$ deep) without allowing air bubbles to accumulate. The speed of the cross-head was $1 \mathrm{~mm} / \mathrm{min}$ and the distance traveled after touching the sample was $3 \mathrm{~cm}$. The test parameters were adhesive force, adhesiveness, apparent modulus, hardness, and hardness work done. The measurements were conducted in triplicate.

\section{Descriptive Analysis}

The panel consisted of 9 women (mean age $=24$, range $=22-27)$ who were selected based on their willingness to participate and time availability. They were mainly graduate students in the Nutrition and Food Science Department at the American University of Beirut. The panelists were briefed about the study but were not informed about the details or the nature of the experimental design. They were all, however, familiar with Labneh and its characteristics. The study was approved by the Institutional Review Board of the American University of Beirut.

The panelists were trained for seven 1-h sessions. During each training session, 3 experimental or other commercial samples labeled with a 3-digit random number were presented to the panelists for assessment. Panelists were asked to examine the samples and to describe the appearance, odor, flavor, texture, and aftertaste of Labneh by providing a list of attributes individually covering each of the aforementioned characteristics. A discussion took place after testing, and the panelists were asked to reach an agreement on the attributes used and to provide and agree on a definition for each attribute. Reference standards were chosen for some attributes and were used to anchor the descriptors on the ballot. In the primary stages of training, the presented samples were of different fat levels and then in later training stages the presented samples were of similar fat levels to increase the level of difficulty of the assessment and to test for consistency among panelists and samples. Statistical analyses were conducted to assess the performance and consistency of the panelists during the training sessions. The final list of 20 attributes with definitions, anchor words, and reference standards is summarized in Table 1.

Panelists attended 6 evaluation sessions conducted over a period of $3 \mathrm{~d}$. Two sessions took place on each day, a morning and an afternoon session. The evaluation sessions took place in the sensory evaluation laboratory of the Nutrition and Food Science department at the American University of Beirut. Panelists were seated 
Table 1. Terms used in descriptive analysis of bovine Labneh

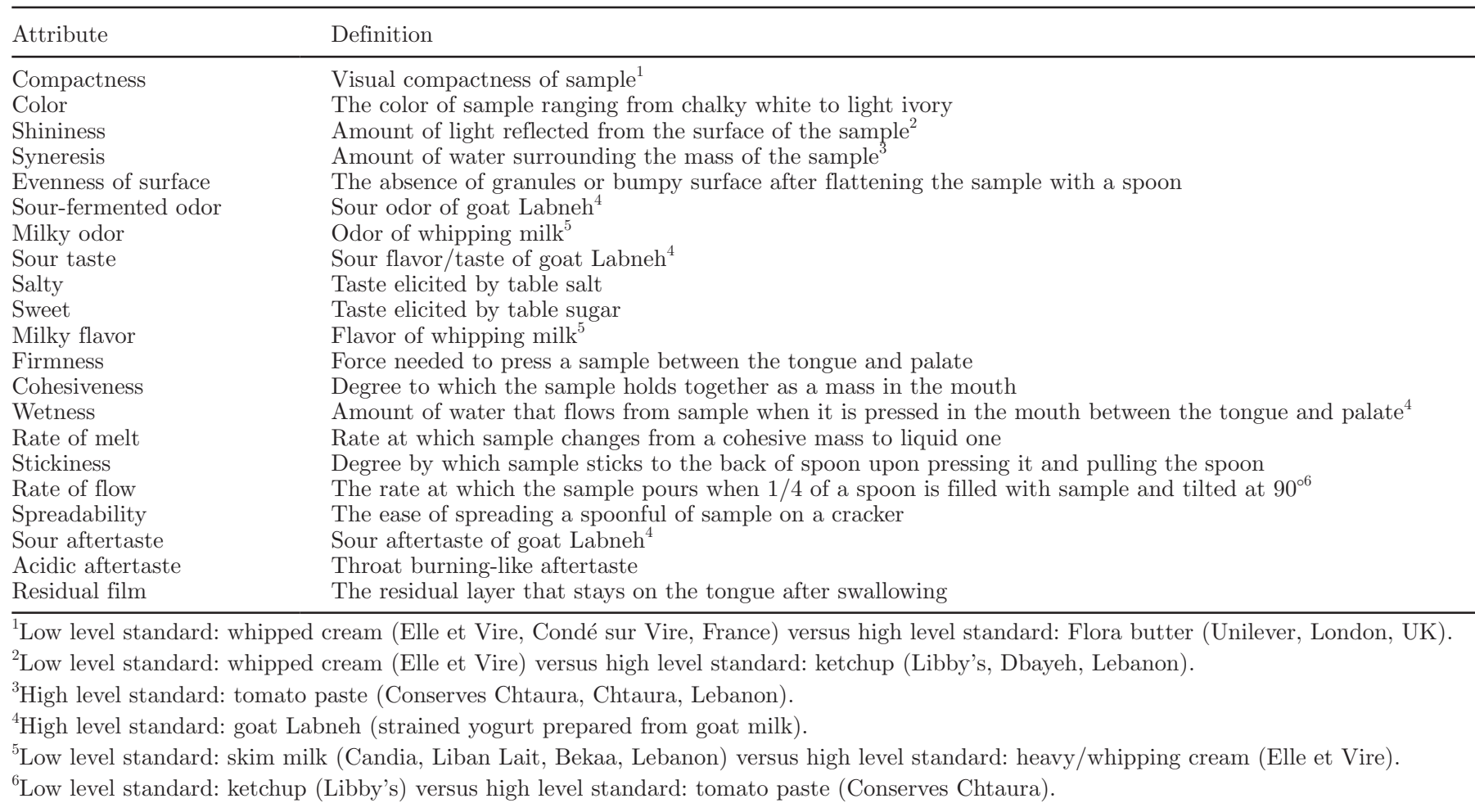

in separate booths with fluorescent lighting. Samples along with the references were prepared $1 \mathrm{~h}$ before the evaluation sessions and stored at $5^{\circ} \mathrm{C}$ in the refrigerator. Samples were presented on a tray in $59-\mathrm{mL}$ plastic containers labeled with 3-digit random numbers. A sensory ballot, napkins, spoons, references, and water were provided along with the samples. Panelists were asked to rate the intensity of each attribute on a $15-\mathrm{cm}$ line scale. The order of presentation of the samples was counterbalanced based on the design for 17 samples, as suggested by Macfie and Bratchell (1989). Panelists were compensated for their participation with a small monetary sum.

\section{Hedonic Evaluation}

Seventy-three panelists (28 males and 45 females, mean age $=21$, range $=18-29)$, who were all Labneh users, participated in the acceptability test. They were students, faculty members, and staff at the American University of Beirut. Panelists were selected based on their willingness to participate and time availability. At the end of testing, a small monetary sum was given to each panelist as compensation for participation.

Each panelist assessed 17 samples; 6 samples were assessed on the first day, another 6 on the second day, and the last 5 samples were assessed on the third day.
Fresh samples were used every day. The samples were presented in 59-mL covered plastic cups and each sample was labeled with a 3-digit random number. Samples were served in a random and counterbalanced manner on a tray. Panelists were also provided with a questionnaire, spoons, napkins, and a cup of water to rinse their mouths between samples. Preparation of the samples took place $1 \mathrm{~h}$ before the tasting sessions and then samples were stored in the refrigerator at $5^{\circ} \mathrm{C}$ until sensory evaluation.

At the beginning of the first tasting session the panelists' questionnaire included questions about the frequency of Labneh consumption, time of consumption (during which meal), and form of consumption. Furthermore, panelists were asked about the factors that drive them to consume Labneh. Panelists were then asked to taste the samples in the presentation order provided and to rate each sample for appearance, flavor, texture, and overall acceptability on a 9-point hedonic scale (1 $=$ dislike extremely to $9=$ like extremely; Peryam and Pilgrim, 1957).

\section{Statistical Analyses}

An ANOVA using the MIXED procedure of SAS (version 8.02, SAS Institute Inc., Cary, NC) was performed to assess the performance of panelists (ability 
to discriminate among samples, reproducibility, and concept alignment) during panel training and to assess the significance of chemical, physical, and sensory differences among the experimental samples in the evaluation sessions. In the statistical model for the descriptive sensory data, the response variable was the sensory attribute of the samples. Factors in the model were brand type (7 brands), fat level (full-fat, reduced-fat, and zero-fat), panelist, and replicate. Panelist was included as a random effect and the other variables were fixed effects in the model. Each of the main effects was tested as well as their interactions. Panelist was not included in the chemical or physical analyses models, and the sensory acceptability model did not include replicate. Significant means for the sensory analyses were separated by Tukey's honestly significant difference test. Significance was pre-established at $\alpha<0.05$. Moreover, principal components analysis was performed using the 34 means obtained from descriptive analysis to determine relationships among attributes and differences among samples in the design.

Internal and external preference mapping was performed on acceptance data of Labneh samples from 73 consumers and on mean attribute scores for Labneh samples from the trained descriptive analysis panel. Both the consumer and descriptive panels evaluated the same 17 commercial Labneh samples. All the attributes evaluated by the descriptive panel were included in this analysis. The internal preference map was created in SAS from the monotonically transformed data, as a substantial improvement in fit was observed going from the factor procedure to the PRINQUAL procedure (from 0.41 to 0.55 , respectively, of the proportion of combined variance for principal components 1 and $2)$. The external preference map was created in SAS using the TRANSREG procedure, which allows for the evaluation of goodness-of-fit to the different models (in this case, vector, circular, and elliptical) on a judgeby-judge basis. All other analyses were also performed using the SAS statistical software.

\section{RESULTS AND DISCUSSION}

\section{Physical and Chemical Analyses}

Results of the chemical analyses are summarized in Table 2 . Brand type had a significant effect $(P<0.001)$ on all composition variables; namely, moisture, fat, ash, $\mathrm{pH}$, nitrogen-free extract (NFE; $P<0.001$ ), and protein $(P<0.05)$, whereas fat level had a significant effect on all the aforementioned chemical variables $(P<$ 0.001) except for NFE. Moreover, the interaction brand $\times$ fat level was significant $(P<0.001)$ for all variables. Moisture, fat content, and $\mathrm{pH}$ differed significantly between full-fat, reduced-fat, and zero-fat Labneh samples, whereby full-fat samples had the highest moisture and $\mathrm{pH}$ levels, followed by the reduced-fat and then the zero-fat samples. The opposite trend was true for the fat content of the samples of the different fat levels. Protein content was highest for reduced-fat Labneh and significantly differed from the levels reported for full-fat and zero-fat samples, whereas ash content was highest for full-fat Labneh and significantly different from that reported for reduced and zero-fat varieties. The content of NFE did not significantly differ between samples. These results were consistent with the findings reported by Kirdar and Gun (2002) and with the expected fat and moisture levels for the different fat categories (LIBNOR, 1999).

The results of the texture analyses are summarized in Table 3 . The ANOVA showed a significant brand effect and brand $\times$ fat level interaction for adhesive force, adhesiveness, apparent modulus, hardness, and hardness work done $(P<0.001)$. Fat level significantly affected apparent modulus, hardness $(P<0.05)$, adhesive force, and hardness work done $(P<0.01)$. Surprisingly, mean comparisons showed significant differences for hardness work done only. Reduced-fat samples did not differ significantly from the other 2 fat levels. The lack of significant differences for other variables was probably due to the wide variations between brands that "diluted" any fat-level effects. Full-fat samples showed significantly higher hardness work done levels than zero-fat samples.

\section{Descriptive Analysis: ANOVA and Tukey Test}

The results of the ANOVA for the descriptive sensory analysis and the least squares means of the 21 sensory attributes for the different fat levels (full-fat, reducedfat, and zero-fat) are summarized in Table 4. The ANOVA revealed significant differences for panelists for all attributes $(P<0.001)$, an expected outcome given the general difference between the panelists in terms of their usage of the $15-\mathrm{cm}$ line scale. Moreover, significant differences were obtained between the 7 brands for all attributes $(P<0.001$, except for color where $P$ was $<0.01)$. Fat level was significant for color, evenness of surface, firmness, wetness, spreadability $(P<0.05)$, syneresis, cohesiveness, rate of melt $(P<0.01)$, sour taste, salty, sweet, sour aftertaste, and acidic aftertaste $(P<0.001)$.

Full-fat, reduced-fat, and zero-fat Labneh samples differed significantly with regard to sour and salty taste, and sour aftertaste $(P<0.05)$, with full-fat samples rating higher than reduced-fat and zero-fat for these 3 attributes. Full-fat samples were also significantly $(P$ $<0.05)$ more yellow and less sweet and possessed a stronger acidic aftertaste than their reduced-fat and 
Table 2. Significance of the effects ( $F$-values) of brand, fat level, and their interactions on the chemical properties and least squares means (mean $\pm \mathrm{SD}$; range in parentheses) of the chemical properties of Labneh samples

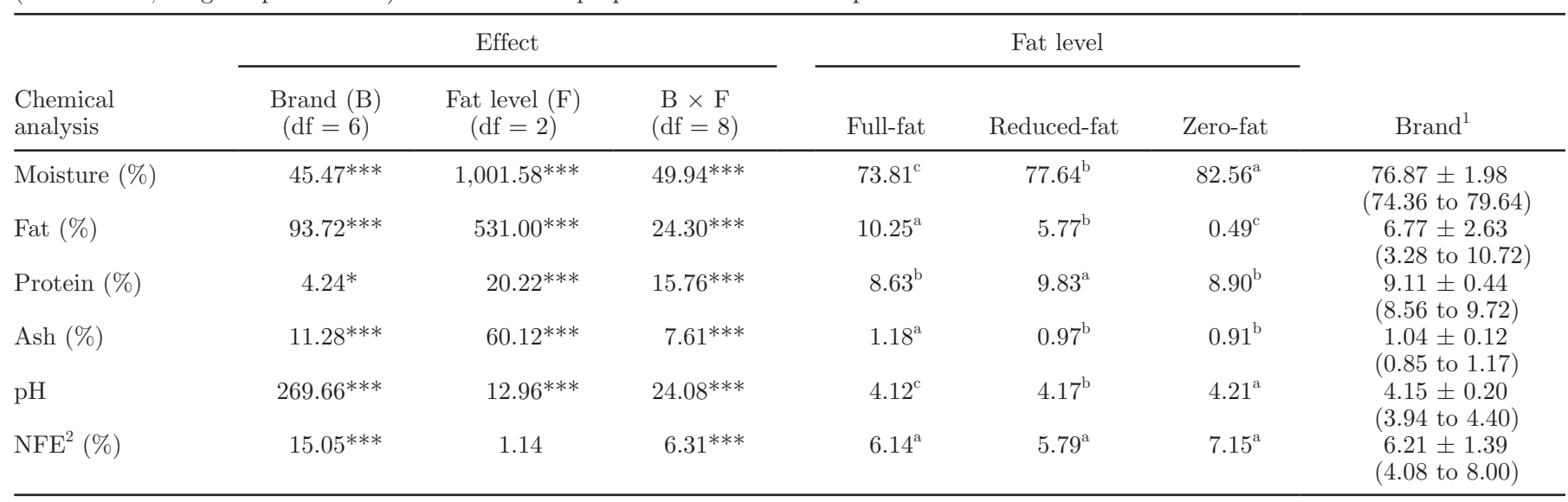

${ }^{a-c}$ Means within a fat level and within a row with different superscripts are significantly different $(P<0.05)$.

${ }^{1}$ Mean \pm SD of LSM of the 7 brands of Labneh; range (minimum to maximum) of LSM in parentheses.

${ }^{2} \mathrm{NFE}=$ nitrogen-free extract.

${ }^{*} P<0.05 ;{ }^{* *} P<0.01 ;{ }^{* * *} P<0.001$.

zero-fat counterparts. The color results were consistent with the findings of Yazici and Akgun (2004), who reported that an increase in the fat content significantly increased the yellow color values of the samples. Zerofat samples had significantly higher ratings for firmness, cohesiveness, and spreadability and lower ratings for wetness, rate of melt, and evenness of surface than full-fat and reduced-fat samples. Reduced-fat Labneh exhibited more syneresis than the full-fat and zero-fat versions. Interestingly enough, the sensory results were not replicated in the instrumental texture results. Sensory results showed differences on several texture attributes between fat levels, whereas instrumental texture analysis did not. This could be another example where sensory analysis could be more sensitive or meaningful than instrumental analysis.

To create a visual profile of product attributes, a spider plot was created by plotting mean intensity values on each scale and then joining the points (Stone and Sidel, 1998). Figure 1 shows attributes of Labneh samples belonging to the 7 brands chosen for the study. Differences in attributes among different brands are most probably due to the differences in production techniques and processing conditions. Previous studies revealed similar descriptive attributes for Labneh in terms of flavor, texture, appearance, aftertaste, and mouthfeel (Modler et al., 1983; Biliaderis et al., 1992; Nsabimana et al., 2005).

Table 3. Significance of the effects ( $F$-values) of brand, fat level, and their interactions on the physical properties and LSM of the physical properties of Labneh samples

\begin{tabular}{|c|c|c|c|c|c|c|c|}
\hline Physical analysis & \multicolumn{3}{|c|}{ Effect } & \multicolumn{3}{|c|}{ Fat level } & Brand $^{1}$ \\
\hline Adhesiveness $(\mathrm{g} \cdot \mathrm{s})$ & $69.60^{* * *}$ & 2.09 & $25.50^{* * *}$ & $-1,145.5$ & $-1,089.92$ & $-1,142.9$ & $\begin{array}{l}-1,139.90 \pm 299.49 \\
(-1,598.55 \text { to }-655.48)\end{array}$ \\
\hline Hardness (g) & $152.37^{* * *}$ & $4.90^{*}$ & $64.97^{* * *}$ & 286.78 & 269.74 & 270.31 & $\begin{array}{l}282.75 \pm 72.35 \\
(149.05 \text { to } 372.75)\end{array}$ \\
\hline Hardness work done $(\mathrm{g} \cdot \mathrm{s})$ & $163.36^{* * *}$ & $8.30^{* *}$ & $60.56^{* * *}$ & $6,892.7^{\mathrm{a}}$ & $6,458.17^{\mathrm{ab}}$ & $6,341.4^{\mathrm{b}}$ & $\begin{array}{c}6,773.31 \pm 1,854.89 \\
(3,342.34 \text { to } 9,267.29)\end{array}$ \\
\hline
\end{tabular}

\footnotetext{
${ }^{\mathrm{a}, \mathrm{b}}$ Means within a fat level and within a row with different superscripts are significantly different $(P<0.05)$.

${ }^{1}$ Mean \pm SD of LSM of the 7 brands of Labneh; range (minimum to maximum) of LSM in parentheses.

${ }^{*} P<0.05 ;{ }^{* *} P<0.01 ;{ }^{* * *} P<0.001$.
} 
Table 4. Significance of the effects of panelist, brand, fat level, replicate, and their interactions on the sensory properties of Labneh samples and LSM of descriptive analysis attributes (rated on a $15-\mathrm{cm}$ line scale)

\begin{tabular}{|c|c|c|c|c|c|c|c|c|c|c|c|c|}
\hline \multirow[b]{2}{*}{ Attribute } & \multicolumn{8}{|c|}{ Effect } & \multicolumn{3}{|c|}{ Fat level $^{1}$} & \multirow[b]{2}{*}{ Brand $^{2}$} \\
\hline & $\begin{array}{l}\text { Panelist (P) } \\
\quad(\mathrm{df}=8)\end{array}$ & $\begin{array}{l}\text { Brand (B) } \\
(\mathrm{df}=6)\end{array}$ & $\begin{array}{l}\text { Fat level }(\mathrm{F}) \\
\quad(\mathrm{df}=2)\end{array}$ & $\begin{array}{l}\text { Replicate } \\
(\mathrm{df}=1)\end{array}$ & $\begin{array}{c}\mathrm{R} \times \mathrm{P} \\
(\mathrm{df}=8)\end{array}$ & $\begin{array}{c}\mathrm{B} \times \mathrm{F} \\
(\mathrm{df}=8)\end{array}$ & $\begin{array}{c}\mathrm{B} \times \mathrm{F} \times \mathrm{P} \\
(\mathrm{df}=64)\end{array}$ & $\begin{array}{c}\mathrm{B} \times \mathrm{F} \times \mathrm{R} \\
(\mathrm{df}=8)\end{array}$ & $\mathrm{FF}$ & $\mathrm{RF}$ & $\mathrm{ZF}$ & \\
\hline Compactness & $18.36^{* * *}$ & $33.95^{* * *}$ & 1.91 & 1.67 & 0.3 & $4.49^{* * *}$ & 0.87 & 1.26 & 8.6 & 8.1 & 9.0 & $\begin{array}{c}8.8 \pm 2.03 \\
(4.7 \text { to } 10.7)\end{array}$ \\
\hline Color & $6.24^{* * *}$ & $3.27^{* *}$ & $4.52^{*}$ & 0.11 & 0.52 & 0.66 & 0.91 & 1.01 & $8.5^{\mathrm{a}}$ & $5.7^{\mathrm{b}}$ & $6.4^{\mathrm{b}}$ & $\begin{array}{l}7.4 \pm 1.73 \\
(5.4 \text { to } 9.6)\end{array}$ \\
\hline Shininess & $15.25^{* * *}$ & $37.61^{* * *}$ & 1.11 & 7.51 & $3.34^{* *}$ & $2.19^{*}$ & 1.32 & 0.54 & 8.1 & 9 & 8.2 & $\begin{array}{l}7.8 \pm 2.24 \\
(5.3 \text { to } 11.7)\end{array}$ \\
\hline Syneresis & $8.40^{* * *}$ & $80.57^{* * *}$ & $5.18^{* *}$ & 2.93 & $3.05^{* *}$ & $7.65^{* * *}$ & 1.04 & 1.89 & $6.7^{\mathrm{b}}$ & $8.3^{\mathrm{a}}$ & $7.0^{\mathrm{b}}$ & $\begin{array}{c}7.4 \pm 3.20 \\
(3.3 \text { to } 11.9)\end{array}$ \\
\hline Evenness of surface & $23.57^{* * *}$ & $15.64^{* * *}$ & $3.93^{*}$ & 0.15 & $2.81^{* *}$ & $6.00^{* * *}$ & 0.69 & 1.11 & $10.2^{\mathrm{a}}$ & $10.2^{\mathrm{a}}$ & $9.1^{\mathrm{b}}$ & $\begin{array}{l}9.9 \pm 1.50 \\
(7.8 \text { to } 11.8)\end{array}$ \\
\hline Sour-fermented odor & $26.65^{* * *}$ & $7.13^{* * *}$ & 2.34 & 0.08 & $2.15^{*}$ & 1.75 & 1.05 & 1.35 & 9.6 & 8.5 & 9.2 & $\begin{array}{l}8.8 \pm 1.52 \\
(6.4 \text { to } 11.3)\end{array}$ \\
\hline Milky odor & $45.38^{* * *}$ & $7.83^{* * *}$ & 1.39 & 3.45 & $2.06^{*}$ & 1.56 & 1.24 & 0.46 & 6.6 & 6.9 & 6.8 & $\begin{array}{l}7.1 \pm 1.19 \\
(5.3 \text { to } 8.9)\end{array}$ \\
\hline Sour taste & $21.79^{* * *}$ & $19.03^{* * *}$ & $15.37^{* * *}$ & 0.42 & 0.76 & $2.10^{*}$ & $1.59^{*}$ & 0.87 & $9.7^{\mathrm{a}}$ & $7.5^{\mathrm{c}}$ & $8.4^{\mathrm{b}}$ & $\begin{array}{l}8.6 \pm 1.76 \\
(6.4 \text { to } 11.7)\end{array}$ \\
\hline Salty & $13.73^{* * *}$ & $9.11^{* * *}$ & $99.45^{* * *}$ & 0.69 & 1.02 & $8.35^{* * *}$ & 1.36 & 1.7 & $9.3^{\mathrm{a}}$ & $7.2^{\mathrm{b}}$ & $5.6^{\mathrm{c}}$ & $\begin{array}{l}7.1 \pm 1.40 \\
(4.5 \text { to } 8.5)\end{array}$ \\
\hline Sweet & $18.89^{* * *}$ & $14.08^{* * *}$ & $20.49^{* * *}$ & 0.03 & $3.45^{* *}$ & 1.74 & $1.94^{* * *}$ & 0.61 & $4.3^{\mathrm{b}}$ & $5.3^{\mathrm{a}}$ & $5.4^{\mathrm{a}}$ & $\begin{array}{l}5.2 \pm 1.18 \\
(3.6 \text { to } 6.8)\end{array}$ \\
\hline Milky flavor & $30.93^{* * *}$ & $9.74^{* * *}$ & 2.55 & 2.42 & $2.28^{*}$ & $2.61^{*}$ & 0.99 & 0.93 & 7.2 & 7.9 & 6.5 & $\begin{array}{l}7.5 \pm 1.27 \\
(5.5 \text { to } 9.5)\end{array}$ \\
\hline Firmness & $31.53^{* * *}$ & $39.62^{* * *}$ & $4.53^{*}$ & 1.83 & 0.9 & $2.60^{*}$ & 1.35 & 1.01 & $7.0^{\mathrm{b}}$ & $6.6^{\mathrm{b}}$ & $7.9^{\mathrm{a}}$ & $\begin{array}{l}7.4 \pm 1.99 \\
(3.8 \text { to } 9.0)\end{array}$ \\
\hline Cohesiveness & $50.50^{* * *}$ & $24.82^{* * *}$ & $6.89^{* *}$ & $3.98^{*}$ & 0.87 & $3.82^{* * *}$ & 1.28 & 0.58 & $7.5^{\mathrm{b}}$ & $7.7^{\mathrm{b}}$ & $8.4^{\mathrm{a}}$ & $\begin{array}{l}7.9 \pm 1.30 \\
(5.6 \text { to } 9.3)\end{array}$ \\
\hline Wetness & $20.47^{* * *}$ & $17.99^{* * *}$ & $3.32^{*}$ & 3.52 & 1.93 & $3.59^{* * *}$ & 0.81 & 0.54 & $8.2^{\mathrm{a}}$ & $8.5^{\mathrm{a}}$ & $7.5^{\mathrm{b}}$ & $\begin{array}{l}8.0 \pm 1.39 \\
(6.5 \text { to } 10.5)\end{array}$ \\
\hline Rate of melt & $27.94^{* * *}$ & $24.71^{* * *}$ & $5.33^{* *}$ & 2.93 & 1.63 & $4.15^{* * *}$ & 1.36 & 1.1 & $9.8^{\mathrm{a}}$ & $9.9^{\mathrm{a}}$ & $8.9^{\mathrm{b}}$ & $\begin{array}{l}9.4 \pm 1.40 \\
(8.1 \text { to } 11.9)\end{array}$ \\
\hline Stickiness & $8.45^{* * *}$ & $4.35^{* * *}$ & 1.66 & 3.19 & 1.41 & 1.43 & 0.89 & 1.92 & 9.1 & 9 & 8.8 & $\begin{array}{l}9.1 \pm 0.87 \\
(7.6 \text { to } 10.4)\end{array}$ \\
\hline Rate of flow & $22.19^{* * *}$ & $23.74^{* * *}$ & 0.56 & $0.59^{*}$ & $2.55^{*}$ & 1.56 & 1.13 & 1.03 & 7.1 & 7.6 & 6.8 & $\begin{array}{l}7.0 \pm 1.67 \\
(5.7 \text { to } 10.3)\end{array}$ \\
\hline Spreadability & $36.69^{* * *}$ & $19.29^{* * *}$ & $4.03^{*}$ & 1.75 & 1.21 & $3.01^{* *}$ & 1.25 & 1.5 & $5.2^{\mathrm{b}}$ & $5.0^{\mathrm{b}}$ & $6.0^{\mathrm{a}}$ & $\begin{array}{c}5.5 \pm 1.23 \\
(3.4 \text { to } 7.0)\end{array}$ \\
\hline Sour aftertaste & $23.11^{* * *}$ & $23.44^{* * *}$ & $15.52^{* * *}$ & 0.41 & 0.69 & $2.32^{*}$ & 1.15 & 1.86 & $9.4^{\mathrm{a}}$ & $7.3^{\mathrm{c}}$ & $8.3^{\mathrm{b}}$ & $\begin{array}{l}8.7 \pm 1.75 \\
(6.5 \text { to } 11.5)\end{array}$ \\
\hline Acidic aftertaste & $11.44^{* * *}$ & $7.73^{* * *}$ & $7.93^{* * *}$ & 0.73 & 0.91 & 1.11 & 1.51 & 0.99 & $8.8^{\mathrm{a}}$ & $7.3^{\mathrm{b}}$ & $7.6^{\mathrm{b}}$ & $\begin{array}{l}8.1 \pm 1.15 \\
(6.4 \text { to } 9.7)\end{array}$ \\
\hline Residual film & $30.93^{* * *}$ & $7.78^{* * *}$ & 1.00 & 0.11 & 1.48 & 0.74 & 1.10 & 1.08 & 7.5 & 6.9 & 7.2 & $\begin{array}{r}7.3 \pm 0.95 \\
(6.5 \text { to } 9.2)\end{array}$ \\
\hline
\end{tabular}

${ }^{\mathrm{a}-\mathrm{c}}$ Means within a fat level and within a row with different superscripts are significantly different $(P<0.05)$

${ }^{1} \mathrm{FF}=$ full-fat; $\mathrm{RF}=$ reduced-fat; $\mathrm{ZF}=$ zero-fat.

${ }^{2}$ Mean \pm SD of LSM of the 7 brands of Labneh; range (minimum to maximum) of LSM in parentheses.

$* P<0.05 ; * * P<0.01 ;{ }^{* * *} P<0.001$. 


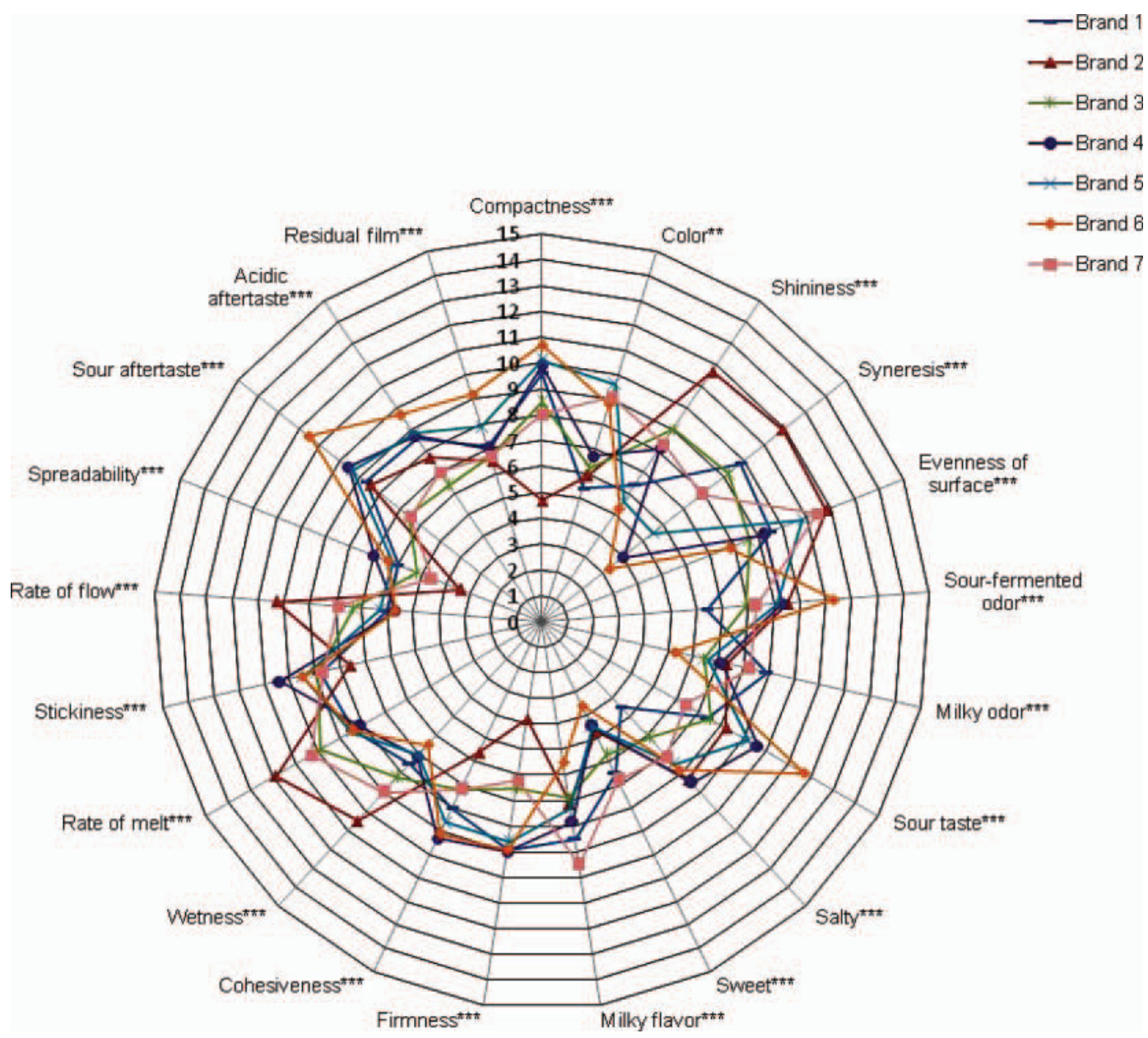

Figure 1. Sensory profiles for 7 brands of Labneh samples. Individual attributes are positioned like the spokes of a wheel around a center (zero or not detected) point, with the spokes representing attribute intensity scales, with higher (more intense) values radiating outward. $* * P$ $<0.01 ; * * *<0.001$. Color version available in the online PDF.

No major inconsistencies were found in the panelists' ratings as shown by the absence of replicate effect except for cohesiveness and rate of flow $(P<0.05)$. The replicate $\times$ panelist interaction was significant for shininess, syneresis, evenness of surface, sweet taste $(P$ $<0.001$ ), sour fermented odor, milky odor, milky flavor, and rate of flow $(P<0.05)$. The brand $\times$ fat level interaction was significant for compactness, syneresis, evenness of surface, salty, cohesiveness, wetness, rate of melt $(P<0.001)$, spreadability $(P<0.01)$, shininess, sour taste, milky flavor, firmness, and sour aftertaste $(P<0.05)$. No significant brand $\times$ fat level $\times$ replicate interactions were found, whereas brand $x$ fat level $x$ panelist was significant for sour taste $(P<0.05)$ and sweet taste $(P<0.001)$. Needless to say, the latter two 3-way interactions are more important than the former 2-way interactions (except panelist $\times$ replicate) because they represent sample $\times$ panelist and sample $\times$ replicate (in both cases sample $=$ brand $\times$ fat level).

\section{Principal Component Analysis}

Figure 2 illustrates the principal components (PC) analysis for the first $2 \mathrm{PC}$ (denoted PC1 and PC2), which accounted for $68.7 \%$ (48.92\% for $\mathrm{PC} 1$ and $19.78 \%$ for $\mathrm{PC} 2$ ) of the variation in the sensory attribute scores. These $2 \mathrm{PC}$ represented 4 different clusters of attributes. The first PC separated the attributes into 2 clusters based on the texture and flavor. The positive side of PC1 included higher values on attributes such as compactness, color, sour fermented odor, saltiness, sour fermented flavor, stickiness, firmness, spreadability, cohesiveness, sour aftertaste, and acidic aftertaste. Principal component 1 separated samples based on brand differences. Brands 1 (full- and reduced-fat), 4 (full- and zero-fat), and 6 (full- and zero-fat) were on the positive side, whereas brands 2, 3 (all 3 fat levels), and 7 (full- and reduced-fat) lay on the negative side of PC1. The zero-fat sample of brand 1 was slightly on 


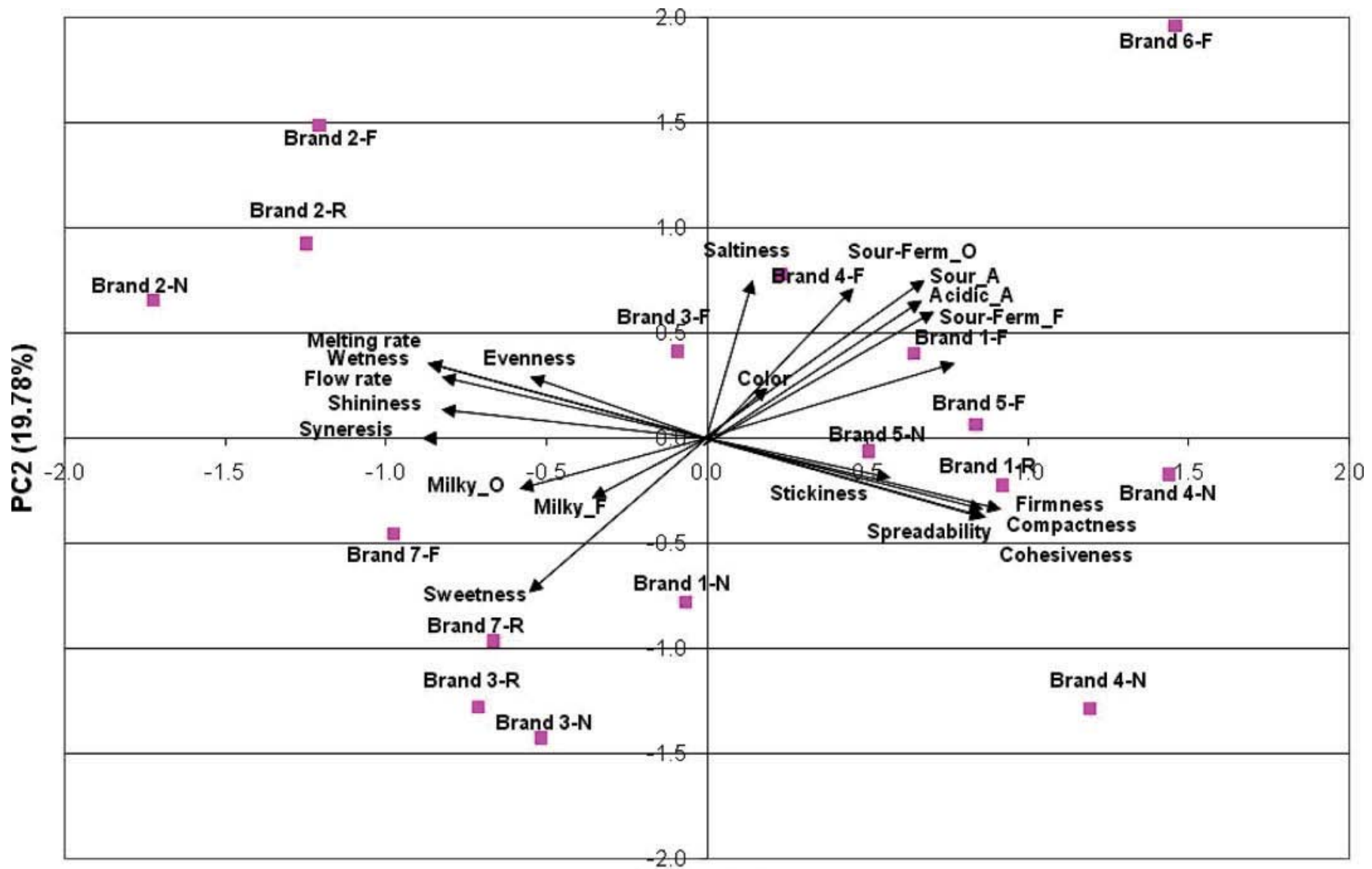

PC1 (48.92\%)

Figure 2. Principal components $(\mathrm{PC})$ plot of Labneh samples and attributes. $\mathrm{F}=$ full-fat; $\mathrm{R}=$ reduced-fat; $\mathrm{N}=$ zero-fat; $\mathrm{A}=$ aftertaste; $\mathrm{O}$ $=$ odor. Color version available in the online PDF.

the negative side of $\mathrm{PC} 1$. The negative side of $\mathrm{PC} 1$ and the positive side of $\mathrm{PC} 2$ quadrant were characterized by attributes typical of full-fat samples such as wetness, rate of melt, rate of flow, evenness of surface, and syneresis.

Principal component 2 separated samples based on fat content. The positive side of PC2 included the full-fat samples for most of the brands (brands 1, 2, 4, 5, and 6) in addition to brand 2 reduced- and zero-fat. The attributes in this side of $\mathrm{PC} 2$ included color, evenness, sour fermented odor, sour fermented flavor, saltiness, melting rate, wetness, rate of flow, shininess and syneresis, sour aftertaste, and acidic aftertaste. The negative side of PC2 included attributes such as stickiness, spreadability, firmness, compactness, cohesiveness, sweetness, milky odor, and milky flavor. The texture attributes mentioned above were more characteristic of the thicker consistency of lower fat samples and included brand 7 full- and reduced-fat samples (brands 1, 3, and 7) and zero-fat (brands 3 and 4).

\section{Hedonic Evaluation}

Results of acceptability tests are summarized in Table 5. Panelist, brand, and fat level effects were significantly different $(P<0.001)$ for overall acceptability, and the acceptability of appearance, flavor, and texture. This is a clear indicator of major differences in acceptability between the different brands and fat levels. A significant panelist $\times$ brand interaction was found for appearance, texture $(P<0.01)$, flavor, and overall acceptability $(P<0.001)$. The panelist $\times$ fat level interaction was significant for acceptability of appearance, texture $(P<0.05)$, flavor, and overall acceptability $(P<0.01)$. The brand $\times$ fat level interaction was also significant for all acceptability variables $(P<$ 0.001 ).

Full-fat, reduced-fat, and zero-fat samples were significantly different $(P<0.05)$ for all tested parameters. Full-fat Labneh was rated highest on the acceptability of appearance, flavor, texture, and overall acceptability, 
Table 5. Significance of the effects of panelist, brand, fat level, and their interactions on the acceptability of Labneh samples and LSM of the acceptability scores (rated on a 9-point category hedonic scale) of Labneh samples

\begin{tabular}{|c|c|c|c|c|c|c|c|c|c|c|}
\hline Acceptability & \multicolumn{6}{|c|}{ Effect } & \multicolumn{3}{|c|}{ Fat level } & Brand $^{1}$ \\
\hline Appearance & $2.86^{* * *}$ & $19.27^{* * *}$ & $20.42^{* * *}$ & $1.27^{* *}$ & $1.26^{*}$ & $6.19^{* * *}$ & $6.54^{\mathrm{a}}$ & $5.93^{\mathrm{b}}$ & $5.39^{\mathrm{c}}$ & $\begin{array}{c}6.19 \pm 0.62 \\
(5.13 \text { to } 6.83)\end{array}$ \\
\hline Texture & $3.21^{* * *}$ & $11.04^{* * *}$ & $34.34^{* * *}$ & $1.31^{* *}$ & $1.28^{*}$ & $6.15^{* * *}$ & $6.59^{\mathrm{a}}$ & $5.83^{\mathrm{b}}$ & $5.20^{\mathrm{c}}$ & $\begin{array}{c}6.13 \pm 0.56 \\
(5.30 \text { to } 6.84)\end{array}$ \\
\hline
\end{tabular}

${ }^{a-c}$ Means within a fat level and within a row with different superscripts are significantly different $(P<0.05)$.

${ }^{1}$ Mean \pm SD of LSM of the 7 brands of Labneh; range (minimum to maximum) of LSM in parentheses.

${ }^{*} P<0.05 ;{ }^{* *} P<0.01 ;{ }^{* * *} P<0.001$.

followed by reduced-fat and then zero-fat Labneh. Acceptability thus clearly decreased as fat level decreased from full fat to zero fat. These findings were consistent with the results of Yazici and Akgun (2004), who found that the average flavor scores for strained yogurt samples were significantly different $(P<0.05)$ and that samples with higher fat content received higher scores. However, previous studies (Abou Jaoude et al., 2010) have demonstrated that this is not always the case in Lebanon for other dairy products, such as Halloumi and Akkawi. The main reason for this is probably that the texture of Labneh is not as negatively affected by fat reduction as it is in white brined cheeses. Furthermore, Lebanon and the Arab region in general (consumers of this product) are witnessing much higher rates of overweight and obesity. A study by Mehio-Sibai et al. (2003) demonstrated that $53 \%$ of Lebanese adults ( $>20$ yr, both sexes) were overweight, including 17\% who were obese. Despite the fact that the prevalence of obesity and overweight is lower than that in the United States, the numbers shown in that study are alarming. Data from other Arab countries reveal higher obesity rates, especially in Kuwait and Jordan. The high prevalence of overweight and obesity in Lebanon has been linked to several factors, including a shift to higher-fat diets in the last $35 \mathrm{yr}$ (between 1963 and 1998; Baba, 2000) and lack of physical exercise. In addition, high overweight and obesity rates were obtained for Lebanese adolescents (Hwalla et al., 2005), although this was more significant for boys. Dieticians in Lebanon are communicating to their patients the need to shift to lower fat options. It seems obvious that the health trends described above and the acceptability results of Labneh call for additional efforts for introducing reduced- or low-fat varieties with high acceptability levels.

\section{Preference Mapping}

Internal Preference Mapping. In the correlation matrix of the monotonically transformed data, PC1 and PC2 accounted for a combined $57.57 \%$ of the variance, with PC1 accounting for 44.21\%. As expected with the monotonic transformation, only $\mathrm{PC} 1$ and $\mathrm{PC} 2$ were retained.

In the internal preference map for the Labneh samples (Figure 3), it was apparent that brand 3 full-fat, brand 4 full-fat, brand 5 full-fat, and brand 6 full-fat, in addition to brand 2 reduced-fat and brand 3 reducedfat were the most liked products. A subset of consumers preferred brand 7 full-fat and brand 5 zero-fat, and another subset of consumers preferred brand 2 zero-fat. The remaining Labneh samples were clustered together along the negative side of the $\mathrm{PC} 1$ axis, indicating that they were not well liked by any of the consumers. It is clear that the lower fat commercial Labneh samples, especially the zero-fat sample, were less liked compared with their higher fat counterparts.

External Preference Mapping. The vector model of the external preference map (Figure 4) produced the best display of the consumer and descriptive analysis panel data. When one takes into consideration the position of the attributes, consumers, and samples in Figures 2 and 4, interesting trends can be observed. Most consumers were drawn toward the Labneh brand 2 full-fat, brand 3 full-fat, and brand 2 reduced-fat. Smaller segments of consumers were noted for other samples, especially for brand 2 zero-fat and to a smaller extent for brand 7 full-fat. All of these samples except brand 7 full-fat were on the negative side of PC1 and the positive side of $\mathrm{PC} 2$. This location (as indicated in Figure 2) is indicative of texture attributes; namely, wetness, rate of melt, rate of flow, evenness of surface, 


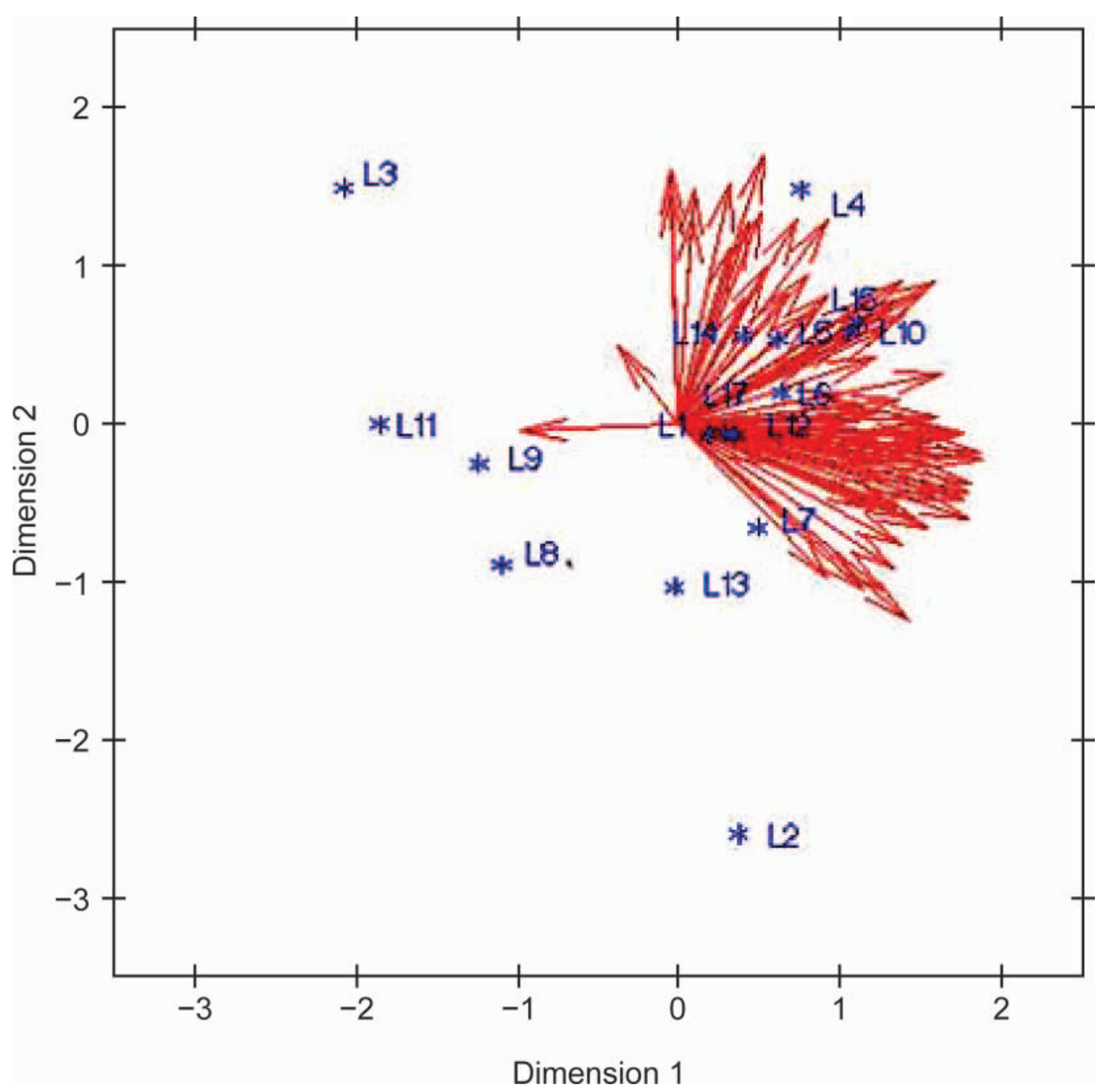

Figure 3. Internal preference map of Labneh samples: L1 = brand 7 reduced-fat; L2 = brand 2 full-fat; L3 = brand 1 zero-fat; L4 = brand 7 full-fat; L5 = brand 5 full-fat; L6 = brand 3 reduced-fat; L7 = brand 2 zero-fat; L8 = brand 1 reduced-fat; L9 = brand 4 zero-fat; L10 = brand 3 full-fat; L11 = brand 6 zero-fat; L12 = brand 2 reduced-fat; L13 = brand 1 full-fat; L14 = brand 5 zero-fat; L15 = brand 6 full-fat; L16 = brand 3 zero-fat; L17 = brand 4 full-fat. Color version available in the online PDF.

and, surprisingly, syneresis. The attributes above were consistent with the characteristics of full-fat samples. The subsegment that existed for brand 7 full-fat on the negative sides of $\mathrm{PC} 1$ and $\mathrm{PC} 2$ was characterized by milky odor and flavor in addition to sweet taste. Very few consumers preferred samples with sourfermented odor and flavor, salty flavor, acidic, and sour aftertastes, and residual film. The same applied, although to a lesser extent, to samples with stickiness, firmness, cohesiveness, and spreadability. These texture attributes are characteristic of the relevant low-fat and zero-fat samples. It is worth noting that all the samples of brand 2 were well liked, even the zero-fat one. This is an interesting trend and a couple of factors may explain it. Either the processing method for this brand produces a high-quality product with appealing characteristics or the brand has a larger market share and thus consumers have already been exposed to it and have experienced a "taste education" phenomenon.

\section{CONCLUSIONS}

The results of the study suggested that chemical and instrumental textural differences existed between samples of different brands and between those possessing different fat levels. Instrumental texture analysis did reveal major differences that were not observed in mean comparisons for fat levels. Sensory analysis showed significant differences between brands for most attributes and suggested that an increased fat level 


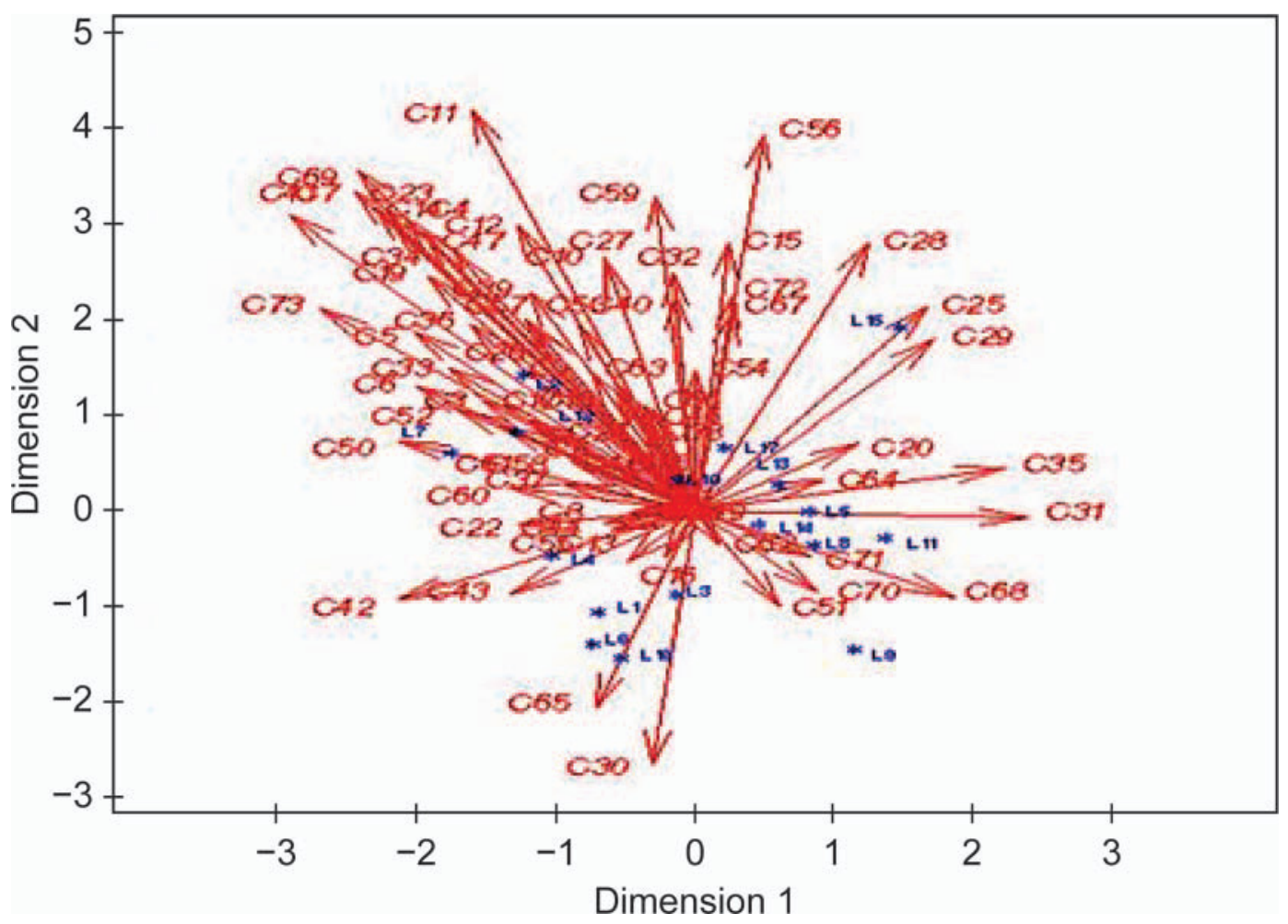

Figure 4. External preference map of Labneh samples: L1 = brand 7 reduced-fat; L2 = brand 2 full-fat; L3 = brand 1 zero-fat; L4 = brand 7 full-fat; L5 = brand 5 full-fat; L6 = brand 3 reduced-fat; L7 = brand 2 zero-fat; L8 = brand 1 reduced-fat; L9 = brand 4 zero-fat; L10 = brand 3 full-fat; L11 = brand 6 zero-fat; L12 = brand 2 reduced-fat; L13 = brand 1 full-fat; L14 = brand 5 . Arrows indicate preferences of 73 consumers $(\mathrm{C} 1$ to $\mathrm{C} 73)$. Color version available in the online $\mathrm{PDF}$.

affected color: full-fat samples were more yellow than their reduced-fat and zero-fat counterparts. Zero-fat samples, on the other hand, rated highest in firmness, cohesiveness, and spreadability. In acceptability tests, full-fat samples rated highest on all attributes followed by the reduced-fat and zero-fat samples. Consumer preference for full-fat Labneh products was further demonstrated by the internal preference map. If one had to conduct the study again, it would have been ideal to collect samples on the day of production from different company plants. Proper storage conditions during transportation and the geographical location of the plant are additional factors to consider. In addition, a better balance between the number of male and female judges in the descriptive panel would have been more representative of the pool of potential descriptive panelists. The results of this study are encouraging, to the extent that fat-reduced varieties received reasonable acceptability scores, although significantly lower than those of their full-fat counterparts. Acceptability is a major factor in potential product sales. In addition, the compliance of the different fat level brands to the specifications set by food regulation agencies (LIBNOR, 1999) in Lebanon is also encouraging. The use of fat replacers during the production process may be one solution for creating a softer texture in zero-fat products thus making them more acceptable to consumers. On the other hand, government inspection activities have to be increased to make sure that all products that are labeled as fat reduced or low in fat are actually consistent with the advertised claims.

\section{ACKNOWLEDGMENTS}

The authors thank John Walker (Statistics Department, California Polytechnic State University, San Luis Obispo, CA), Imad Toufeili, Rosalie Karam, Atallah Louka, Roula Mezher, and Mathieu Najm (all of the Nutrition and Food Sciences Department, Faculty of Agricultural and Food Sciences, American University of Beirut, Beirut, Lebanon) for technical assistance and all the panelists who took part in this study. Support by the University Research Board at the American University of Beirut is also greatly appreciated.

\section{REFERENCES}

Abou Jaoude, D., A. Olabi, N. E. Najm, A. Malek, C. Saadeh, E. Baydoun, and I. Toufeili. 2010. Chemical composition, mineral content and cholesterol levels of some regular and reduced-fat white 
brined cheeses and strained yogurt (Labneh). Dairy Sci. Technol. 90:699-706. doi:10.1051/dst/2010026.

Abu-Jdayil, B., R. Y. Jumah, and R. R. Shaker. 2002. Rheological properties of a concentrated fermented product, Labneh, produced from bovine milk: Effect of production method. Int. J. Food Properties 5:667-679.

AOAC. 2000. Official Methods of Analysis. Vol. II. 17th ed. Association of Official Analytical Chemists. Gaithersburg, MD.

Baba, N. H. 2000. Dietary intake and nutrition related disorders in Lebanon. Nutr. Health 23:33-40.

Biliaderis, C. G., M. M. Khan, and G. Blank. 1992. Rheological and sensory properties of yogurt from skim milk and ultrafiltered retentates. Int. Dairy J. 2:311-323.

Brauss, M. S., R. S. T. Linforth, I. Cayeux, B. Harvey, and A. J. Taylor. 1999. Altering the fat content affects flavor release in a model yogurt system. J. Agric. Food Chem. 47:2055-2059.

Hatchwell, L. C. 1994. Overcoming flavor challenges in low fat frozen desserts. Food Technol. 48:98-102.

Hwalla, N., A. Mehio-Sibai, and N. Adra. 2005. Adolescent obesity and physical activity. Page 42-50 in Nutrition and Fitness: Obesity, the Metabolic Syndrome, Cardiovascular Disease and Cancer. A. P. Simopoulos, ed. Karger AG, Basel, Switzerland.

Kirdar, S., and I. Gun. 2002. Microbiological, chemical and physical properties of strained yoghurt consumed in Burdur market. Gida 27:59-64.

LIBNOR. 1999. Al-Labneh, Standard No. 23. Lebanese Standards Institution-LIBNOR, Sin El Fil, Lebanon.

Macfie, H. J., and N. Bratchell. 1989. Designs to balance the effect of order of presentation and first-order carryover effects in hall tests. J. Sens. Stud. 4:129-148.

Malek, A., S. Shadarevian, and I. Toufeili. 2001. Sensory properties and consumer acceptance of concentrated yogurt made from cow's, goat's and sheep's milk. Milchwissenschaft 56:687-690.
Mehio-Sibai, A., N. Hwalla, N. Adra, and B. Rahal. 2003. Prevalance and covariates of obesity in Lebanon: Findings from the first epidemiological study. Obes. Res. 11:1353-1361.

Modler, H. W., M. E. Larmond, C. S. Lin, D. Froelich, and D. B. Emmons. 1983. Physical and sensory properties of yogurt stabilized with milk proteins. J. Dairy Sci. 66:422-429.

Mohameed, H. A., B. Abu-Jdayil, and A. Al-Shawabkeh. 2004. Effect of solids concentration on the rheology of Labneh (concentrated yogurt) produced from sheep milk. J. Food Eng. 61:347-352.

Nsabimana, C., B. Jiang, and R. Kossah. 2005. Manufacturing, properties and shelf life of Labneh: A review . Int. J. Dairy Technol $58: 129-137$

Özer, B. H. 2006. Production of concentrated products. Pages 128-155 in Fermented Milks. A. Y. Tamime, ed. Blackwell Publishing, Oxford, UK.

Özer, B. H., and R. K. Robinson. 1999. The behaviour of starter cultures in concentrated yoghurt (Labneh) produced by different techniques. Lebenson. Wiss. Technol. 32:391-395.

Özer, B. H., R. A. Stenning, A. S. Grandison, and R. K. Robinson. 1999. Rheology and microstructure of Labneh (concentrated yogurt). J. Dairy Sci. 82:682-689.

Peryam, D. R., and F. J. Pilgrim. 1957. Hedonic scale method of measuring food preferences. Food Technol. 11:9-14.

Stone, H., and J. L. Sidel. 1998. Quantitative descriptive analysis: Developments, applications, and the future. Food Technol. 52:48-52.

Tamime, A. Y., and R. K. Robinson. 2007. Yogurt Science and Technology. 3rd ed. Woodhead Publishing Ltd., Cambridge, UK.

Yazici, F., and A. Akgun. 2004. Effect of some protein based fat replacers on physical, chemical, textural, and sensory properties of strained yoghurt. J. Food Eng. 62:245-254. 